Faculdade de Ciências Econômicas UFRGS
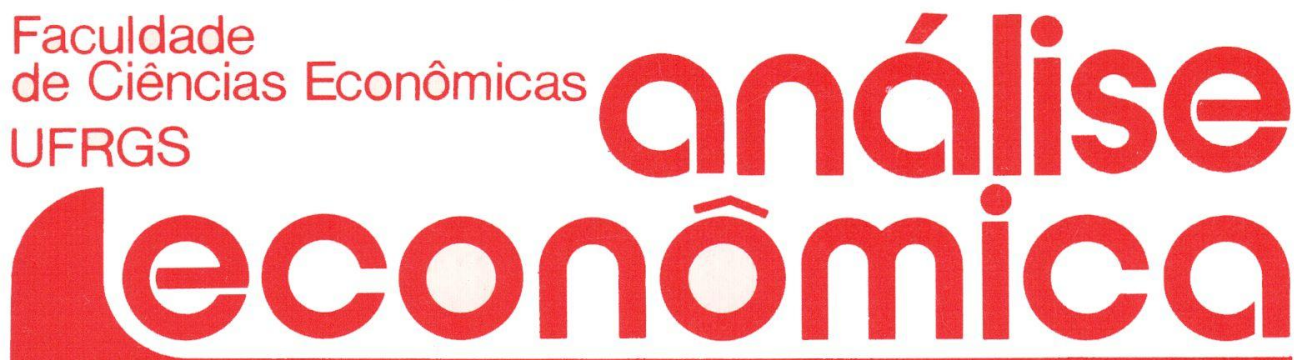

- apResentaÇ̃o à "ANálise simples da MAXIMIZAÇÂO DO BEM-ESTAR" DE FRANCIS BATOR

João Rogério Sanson

- UMA ANÁlise SIMPLES da MAXIMIZAÇÃo do BEM-ESTAR

Francis M. Bator

- O Regime de câmbio flutuante numa ETAPA DE TRANSICÃO

Francisco Eduardo Pires de Souza

- AgREgAdos monetÁRIOS, NIVEL DE RENDDA NOMINAL, TAXA DE INFLAÇÃO: UMA ANÁLISE DA CAUSALIDADE NO BRASIL, 1972 A 1987

Divanildo Triches

- A EXPlosão de CONSUMO do CRUzAdo Marcelo Cortes Neri

- METOdologia de PLANEJAMENTO do SETOR ELÉTRICO: QUESTŐES DOS ANOS 90

João Lizarolo de Araújo

Adilson de Oliveira

- CONCENTRAÇÃo INDUSTRIAL NO BRASIL SEGUNDO OS CENSOS, 1907-1980

Olimpio J. de Arrouxelas Galvão

- O VAlor, A RIQUEza e A TEORIA DE SMITH Reinaldo A. Carcanholo

- O "ESTADO ESTACIONÁRIO" e A ECONOMIa CLÁSSICA

Gentil Corazza

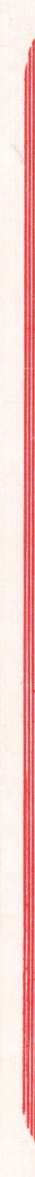
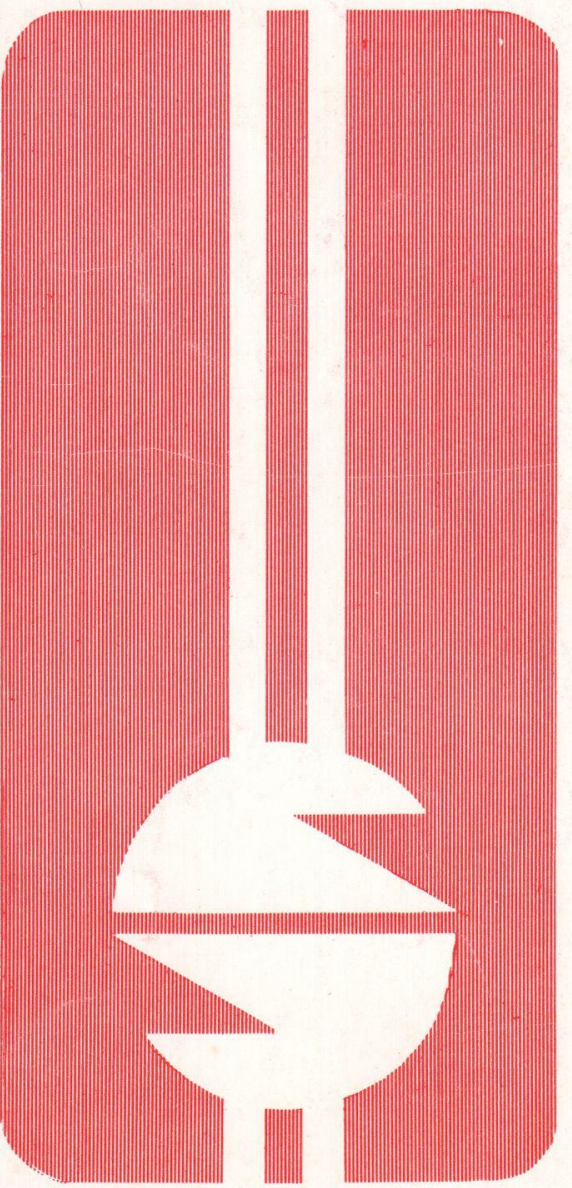
UNIVERSIDADE FEDERAL DO RIO GRANDE DO SUL

Reitor: Prof Tuiskon Dick

FACULDADE DE CIÊNCIAS ECONÔMICAS

Diretora: Prof ${ }^{\text {a }}$ Yeda Rorato Crusius

CENTRO DE ESTUDOS E PESQUISAS ECONÔMICAS

Diretor: Reinaldo Ignacio Adams

DEPARTAMENTO DE CIÊNCIAS ECONÔMICAS

Chefe: Prof. Pedro Cezar Dutra Fonseca

CURSO DE PÓS-GRADUAÇĀO EM ECONÔMIA

Coordenador: Prof. Nali de Jesus de Souza

CURSO DE PÓS-GRADUAÇĀO EM ECONOMIA RURAL

Coordenador: Prof. Atos Freitas Grawunder

CONSELHO EDITORIAL: Achyles Barcelos da Costa, Aray Miguel Feldens, Atos Freitas Grawunder, Carlos Augusto Crusius, Ernani Hickmann, João Rogério Sanson, Juvir Luiz Mattuella, Maria Imilda da Costa e Silva, Nali de Jesus de Souza, Nuno Renan Lopes de Figueiredo Pinto, Otilia Beatriz Kroeff Carrion, Otto Guilherme Konzen, Paulo Alexandre Spohr, Pedro Cezar Dutra Fonseca, Reinaldo Ignacio Adams, Roberto Camps Moraes, Valter José Stülp, Yeda Rorato Crusius, David Garlow (Wharton Econometrics Forecasts Association, E.U.A.), Edgar Augusto Lanzer (UFSC), Eleutério F. S. Prado (USP), Fernando Holanda Barbosa (FGV/RJ), Gustavo Franco (PUC/RJ), Joaquim Pinto de Andrade (UNB), Juan H. Moldau (USP), Werner Baer (Univ. de Illinois, E.U.A.)

COMISSÃO EDITORIAL: Atos Freitas Grawunder, Pedro Cezar Dutra Fonseca, Reinaldo Ignacio Adams e Roberto Camps Moraes.

EDITOR: Nali de Jesus de Souza

SECRETARIA: Maria Ivone de Mello (normalização), Vanete Ricacheski (revisão de textos), Zélide Bregalda (Secretária)

FUNDADOR: Prof. Antônio Carlos Santos Rosa

Os materiais publicados na revista Análise Econômica são de exclusiva responsabilidade dos autores. $\dot{E}$ permitida a reprodução total ou parcial dos trabalhos, desde que seja citada a fonte.

Aceita-se permuta com revista congêneres. Aceitam-se, também, livros para divulgação, elaboração de resenhas ou recensões.

Toda correspondência, material para publicaçāo (vide normas na $3^{\mathrm{a}}$ capa), assinaturas e permutas devem ser dirigidos ao seguinte destinatário:

PROF. NALI DE JESUS DE SOUZA

Revista Análise Econômica

Av. João Pessoa, 52

90.040 - PORTO ALEGRE (RS), BRASIL

Telefones: (0512) 28.1633; 24.6022; 26.0012 - Ramals 3440 e 3507

FAX: (0512) 25.5253 


\title{
O REGIME DE CÂMBIO FLUTUANTE NUMA ETAPA DE TRANSIÇÃO
}

\author{
Francisco Eduardo Pires de Souza *
}

Este trabalho busca discutir os dilemas envolvidos na definição de uma política cambial, na transição da situação de alta inflação vivida pela economia brasileira nos últimos anos, para um regime de estabilidade de preços. Argumenta-se que a escalada inflacionária da década de 80 levou a um esgotamento do sistema de minidesvalorizaçōes cambiais. Discute-se os enormes problemas associados à fixação da taxa de cámbio. Conclui-se que, embora o câmbio livremente flutuante não seja uma alternativa desejável a longo prazo, um regime de câmbio flutuante administrado constitui a alternativa menos problemática na etapa de transição para a estabilidade dos preços.

\section{INTRODUÇĀO}

Na primeira metade de seus 22 anos de existência, o regime de minidesvalorizações cambiais foi considerado um sucesso. Concebido como uma alternativa à instabilidade gerada pelo sistema de taxas nominais fixaś numa economia inflacionária, sua regra básica consistia na fixaçāo, pelo Banco Central, de valores para a taxa de câmbio que eram moditicados a intervalos muito curtos, procurando-se manter a paridade do poder de compra da moeda frente ao dólar ou a uma cesta de moedas'. A exemplo de outras inovações institucionais destinadas a neutra-

- Professor da Faculdade de Economia da UFF e do Instituto de Economia Industrial da UFRJ.

1 Inicialmente, os intervalos eram irregulares, variando na maior parte das vezes entre 30 e 60 dias. Progressivamente foram se encurtando, atê tornarem-se diários em 1985. A polltica buscou, em determinadas fases, manter a paridade frente ao dolar e, em outras, a paridade frente a uma cesta de moedas relevantes.

ANÁLISE ECONÓMICA

ANO 9 № 15

MARÇO/91

p.59-77 
lizar os efeitos da inflação sobre o comportamento dos agentes económicos, a indexação cambial começou a apresentar problemas crescentes ao longo dos 80 , que levaram à sua virtual inviabilização no final dessa década. Em março de 1990, com o lançamento do programa de estabilização do governo Collor, um novo regime cambial, baseado em taxas flutuantes, vem por fim substituir as velhas regras e mecanismos cambiais.

O processo de esgotamento no regime de minidesvalorizações será discutido no item 2 a seguir. A terceira seção do trabalho examina as dificuldades para a correção do desalinhamento cambial ocorrido sob o regime de minidesvalorizaçôes (e apesar dele) ao longo dos últimos anos. Complementa essa discussão um brevissimo item que trata das dificuldades técnicas para aferir o nivel sustentável da taxa de câmbio. $\mathrm{Na}$ seção subseqüente discute-se, então, até que ponto a alternativa adotada pelo governo, de mudança para um regime de câmbio flutuante, constitui uma resposta satisfatória ao desafio representado pela necessidade de realinhar o câmbio e, simultaneamente, estabilizar a economia. Buscam-se também reunir elementos, para responder à indagaçấo de se o novo regime constitui um objetivo desejável para o longo prazo. O último item do trabalho apresenta muito resumidamente algumas conclusões a partir da análise anterior.

\section{A DECADÊNCIA DO SISTEMA DE MINIDESVALORIZAÇÕES}

Conforme se esperava à época, o principal mérito do extinto regime de minidesvalorizações durante o período de sucesso que se seguiu à sua introdução, em agosto de 1968, foi o de ter promovido uma estabilizaçăo da taxa de câmbio real. Em conseqüencia, criou-se um ambiente favorável à expansão firme e uniforme do comércio exterior, ao mesmo tempo em que se reduzia a volatilidade até entẫo observada em alguns fluxos do balanço de pagamentos - principalmente os de capitais ${ }^{2}$. Em particular, atribui-se à estabilidade do câmbio real um peso importante na determinação do excelente desempenho das exportações brasileiras de produtos manufaturados de 1968 a 1980. Neste período, as vendas brasileiras destes produtos cresceram a $34 \%$ a.a., contra $10 \%$ a.a. para as exportações mundiais em valor, nesta mesma categoria de bens.

2 Vide a respeito Suplicy (1976, p. 172-74). 
Com uma maxidesvalorização do cruzeiro de $30 \%$, em dezembro de 1979, o então ministro Delfim Neto inauguraria uma nova era, em que a regra das minidesvalorizações seria por diversas vezes violada, seja em função de crises cambiais (quando desvalorizaçōes reais discretas eram obtidas por meio de "maxis" ou "midis"), seja em função de programas de combate à inflação (quando valorizaçōes reais decorriam de congelamentos da taxa).

Independentemente da manipulação deliberada dos "policy makers", a própria aceleração inflacionária minou a regra que garantia a manutenção da paridade do poder de compra da moeda. De fato, na medida em que a curva ascendente dos preços afasta-se de um comportamento próximo à inércia, rumo a um processo de franca aceleração - como na segunda metade dos anos 80 -, a regra de pós-fixaçāo corrói os niveis reais da taxa de câmbio. A taxa de inflação oficial de cada mês - usada como guia para a política cambial - passou a ser (devido às defasagens inerentes à computação dos indices de preços) invariavelmente inferior à elevação dos preços em curso. Este fenômeno alcançou sua expressão máxima nos 12 meses anteriores ao Plano Collor, quando a moeda doméstica sofreu uma valorização real de $64 \%^{3}$ apesar da rigorosa correção do preço oficial do dólar pela inflação oficial do mês.

Ao longo da década de 80 , portanto, a política cambial foi incapaz de evitar dois tipos de problemas que tinham sido exatamente o alvo da política de minidesvalorizaçōes: a variabilidade, e o desalinhamento da taxa de câmbio real ${ }^{4}$. $O$ gráfico a seguir ilustra 0 aumento da volatilidade da taxa de câmbio real efetiva a partir de 1980, bem como a tendência a uma valorização persistente na segunda metade da década.

3. A valorizaçăo foi aqui medida como o aumento do valor real do cruzeiro em relaçăo ao dólar, ou, o que é o mesmo, como a elevaçăo necessária da cotaçăo oficial do dólar para voltar a seu nivel real anterior. O findice de preços doméstico empregado foi o IPA-OG industrial.

4 A variabilidade ou volatilidade da taxa de câmbio é entendida como a variaçăo a curto prazo, dia a dia, ou mês a més, da taxa de câmbio; enquanto o desalinhamento é considerado como um afastamento mais permanente em relaçăo a uma taxa considerada como de equillorio. De tal maneira que pode haver volatilidade com ou sem desalinhamento, $\theta$ vice-versa. Vide a propósito Williamson (1985, p. 9 e 10). 


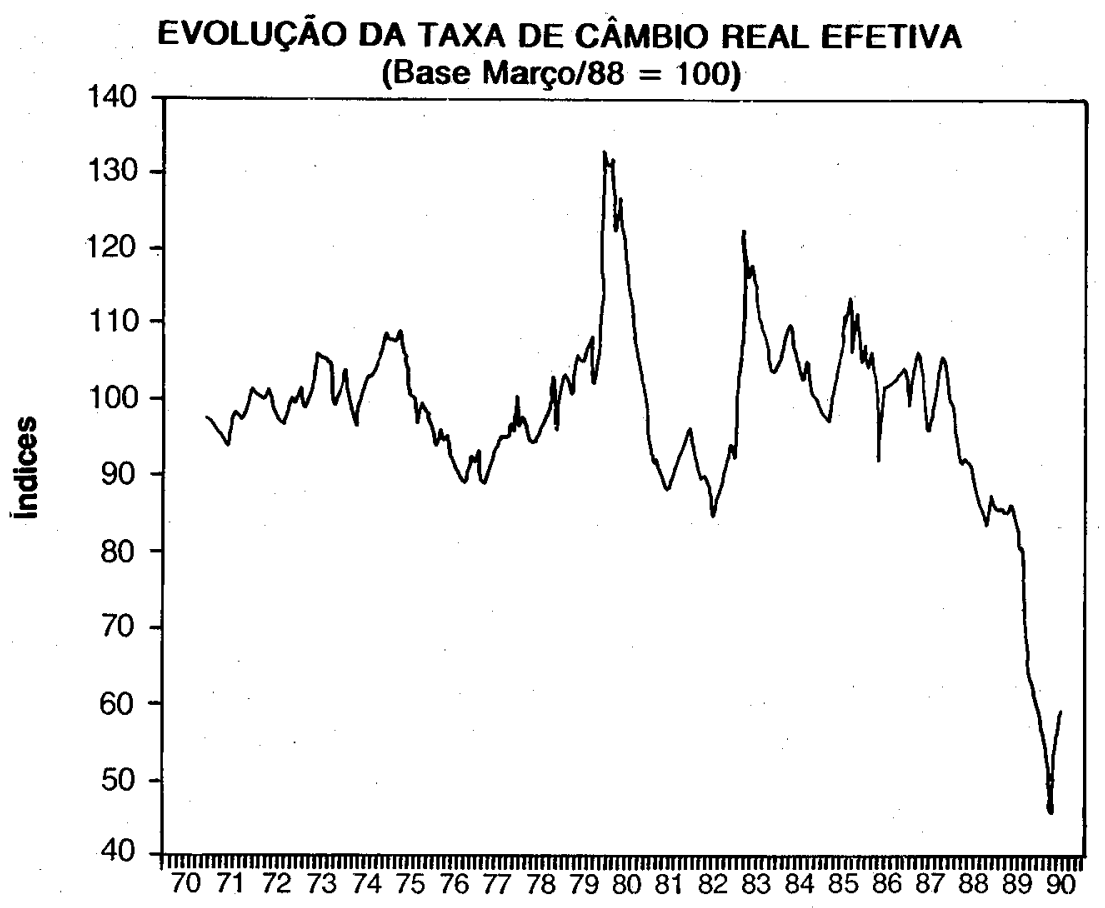

ANOS

Fontes: Banco Central, Boletim Mensal), vários números; e FMl, International Financial Statistics, vários números. A elaboração da série é de Edson R. Barreto Jr., a quem agradeço a colaboraçăo.

O primeiro fenômeno - a volatilidade - tem sido tradicionalmente considerado como um defeito sério de um regime cambial. Além de ampliar a incerteza que envolve o processo de decisão empresarial, inibindo a expansão do comércio exterior, provoca movimentos especulativos que criam sérias dificuldades para a gestão das reservas internacionais pelas autoridades monetárias. Normalmente associada a regimes de taxas flutuantes, a instabilidade real do câmbio ocorre no Brasil em magnitude relativamente elevada nos anos 80 - apesar do regime de câmbio fixado pelo governo - como decorrência da volatilidade da taxa 
de inflação5. A tabela 1, a seguir, fornece uma medida da oscilação da taxa de câmbio real entre 1973 e 1990, através da qual podemos perceber um inequivoco aumento da volatilidade a partir da virada da década de 70 para a de 80 .

\section{TABELA 1}

Volatilidade da Taxa de Câmbio Real (Cr\$ / US\$) *

\begin{tabular}{cc}
\hline PERIODO & VARIAÇÃO \% \\
\hline $1973-75$ & $3.0 \%$ \\
$1976-78$ & $2.4 \%$ \\
$1979-81$ & $8.2 \%$ \\
$1982-84$ & $8.2 \%$ \\
$1985-87$ & $6.7 \%$ \\
$1988-90$ & $13.2 \%$ \\
\hline
\end{tabular}

* Volatilidade medida pelo coeficiente de variaçáo da taxa de cámbio real média mensal em relaçăo a uma média móvel bienal.

Fonte: Banco Central, Boletim Mensal e Fundaçăo Getúlio Vargas. Elaboraçăo prơpria.

Mais grave, entretanto, vinha sendo o problema do persistente e cada vez mais amplo desalinhamento da taxa de câmbio. Deixando para discutir mais à frente as dificuldades teóricas envolvidas na definição de desalinhamento, cabe registrar por ora que, em fevereiro de 1990, às vésperas da posse do governo Collor, havia uma indiscutivel defasagem do câmbio, independentemente dos critérios utilizados para sua aferição. A título de ilustração, a tabela 2 , a seguir, mostra o atraso cambial frente ao dólar e a uma cesta de moedas, de acordo com diversos indices de preços, e por comparação com distintos periodos base. Os percentuais da tabela representam as correções necessárias na taxa de câmbio, para que seu valor real retornasse ao verificado em cada um dos períodos base.

5 Sendo a taxa de câmbio real e $(r)$ igual á taxa nominal multiplicada pela relaçăo entre os indices de inflação externa e interna ( $\left.e_{.} p^{\star} / p\right)$, e dado que $p^{*}$ varia pouco, a volatilidade podena teoricamente provir tanto de variaçóes em e como em p. As "maxis" atuaram sobre a primeira variável, mas o descontrole inflacionário (volatilidade de $p$ ) teve um papel ainda mais decisivo: 


\section{TABELA 2}

\section{DEFASAGEM DA TAXA DE CÂMBIO REAL EM FEVEREIRO DE 1990 COM RELAÇĀO A DISTINTAS BASES}

\begin{tabular}{|c|c|c|c|c|c|}
\hline \multirow{2}{*}{$\begin{array}{c}\text { Período } \\
\text { Base }\end{array}$} & \multicolumn{4}{|c|}{$\begin{array}{l}\text { Taxa Real Cr\$ / US \$ de Acordo } \\
\text { com Diferentes Deflatores }\end{array}$} & \multirow{2}{*}{$\begin{array}{r}\text { Taxa de } \\
\text { Câmbio } \\
\text { Efetiva } \\
\text { Rea }\end{array}$} \\
\hline & IPA-ind & INPC & IGP & $\begin{array}{l}\text { Salário } \\
\text { FIESP }\end{array}$ & \\
\hline Março de 86 & $104 \%$ & $89 \%$ & $93 \%$ & $45 \%$ & $89 \%$ \\
\hline Média de 87 & $91 \%$ & $64 \%$ & $72 \%$ & $41 \%$ & $91 \%$ \\
\hline Média de 88 & $65 \%$ & $58 \%$ & $54 \%$ & $31 \%$ & $67 \%$ \\
\hline Média de 89 & $47 \%$ & $30 \%$ & $31 \%$ & $6 \%$ & $3 \%$ \\
\hline
\end{tabular}

Fontes: Banco Central, Fundaçåo Getúlio Vargas, IBGE e FIESP.

Elaboraçăo: Boletim de Conjuntura do IEI / UFRJ

É surpreendente que, diante da realidade retratada no quadro aci$\mathrm{ma}$, não tenha ocorrido um colapso das vendas ao exterior. Entre os fatores que, certamente, postergaram os efeitos nocivos do desalinhamento cambial sobre o comportamento das exportações, pode-se destacar. a fraqueza da demanda doméstica no periodo em que a defásagem se tornou mais aguda; a resistência dos exportadores a abandonar posições conquistadas no mercado externo, antes de saber se o baixo nivel do câmbio real seria um fenômeno permanente ou meramente transitório; a contração dos salários reais, resultando numa queda da relação câmbio/salário um pouco inferior à redução da taxa de câmbio real deflacionada por outros índices de preços; e, para alguns setores, rentabilidade compensatória derivada do subfaturamento num contexto de elevado ágio do dólar paralelo sobre o oficial. De qualquer maneira, em 1989 , os efeitos da defasagem já eram perceptiveis. Nesse ano, apesar do comportamento altamente favorável do comércio mundial - patente numa expansão de $8 \%$ no valor das transações - as exportações brasileiras de manufaturados sofreram uma queda de $3 \%$.

A mudança de governo com a edição de um plano de estabiliza- 
ção radical era um momento para uma mudança de vulto na política cambial. De um lado, seria necessário fazer uma grande correção no preço da divisa. Mas, além disso, haveria que repensar o regime cambial. Reintroduzir uma regra de indexação cambial a partir de um novo nivel (estabelecido por uma maxi) num contexto de desindexação da economia, seria contraproducente do ponto de vista da estabilização caso fosse adotada uma taxa fixa (como se tentou fazer no Cruzado). Um problema óbvio seria, nesse caso, que taxa fixar. A esse propósito, cabe reconhecer que importantes mudanças ocorridas no plano interno e externo removeram as referências a que se poderia recorrer para estimar uma taxa que se pudesse considerar como satisfatória.

\section{PROBLEMAS NA TRANSIÇÃo PARA UM REGIME DE ESTABILIDADE DE PREÇOS E DE TAXAS FIXAS DE CÂMBIO}

Uma condição básica para que taxas fixas de câmbio funcionem como uma âncora para o processo de estabilização é que haja livre conversibilidade. A possibilidade aberta aos agentes econômicos de trocar a moeda doméstica por moeda estrangeira no volume desejado a um preço fixo, na medida em que se reproduza no tempo, pode ser um instrumento poderoso para persuadi-los da estabilidade monetária. Mas isto supõe que o governo pratique uma política monetária (escorada na politica fiscal) compatível com a taxa fixa em condições de conversibilidade. Se, em vez disso, o financiamento de um déficit público exige uma injeção constante de moeda na economia, o aumento da liquidez doméstica levaria (por exemplo, via baixa da taxa de juros) a um aumento da demanda por moeda estrangeira que, se não revertida, iria corroendo progressivamente as reservas do Banco Central, até inviabilizar a estabilidade da taxa de câmbio. Menos do que um substituto para os instrumentos convencionais de política antiinflacionária, a fixação da taxa de câmbio operaria como um elemento coadjuvante.

$O$ papel coadjuvante consistiria basicamente em influenciar diretamente os custos e os preços dos produtos competitivos com bens importados, e de exercer uma influência importante sobre as expectativas, afetando, com isso, as políticas dos setores fixadores de preços. Mas aqui também o câmbio não poderia funcionar como uma âncora solitária. $\mathrm{Na}$ ausência de uma desindexação completa da economia, a elevação dos salários e de outros rendimentos e custos (reajustados pela in- 
flação passada), produziria uma sobrevalorização cambial que inviabilizaria o experimento, como ocorreu no Chile no final dos 70 e início dos 80 (vide Dornbusch, 1986, p. 323-28).

Mas, mesmo admitindo uma política macroeconômica coerente, $e$ uma desindexação global, a fixação da taxa de câmbio, ainda assim, é problemática. $A$ escolha do nível apropriado no qual será congelado o preço da moeda estrangeira encerra um dilema para as autoridades. Senão vejamos.

Um superdimensionamento da desvalorização traria ônus politicos e econômicos superiores ao necessário, podendo danificar a própria capacidade de implementação da política de estabilização. Muito concisamente, os custos econômicos dessa medida seriam:

- o encarecimento da dívida externa em moeda doméstica, afetando pesadamente, em países como o Brasil, as finanças da administração direta e das empresas estatais; em conseqüencia, o déficit público seria ampliado, e maiores aumentos seriam requeridos nas tarifas do setor público, em ambos os casos atingindo negativamente a política antiinflacionária;

- o aumento dos preços dos bens "tradables", que se refletiria diretamente nos índices de preços, além do impacto mais difundido sobre os custos da economia;

- alguma deterioração dos termos de troca e, por conseqüência, uma redução no nível de renda real;

- mudanças na distribuição de renda, muito possivelmente aietando negativamente os salários reais.

No plano político, a desvalorização, na medida em que resulta de um ato do poder público, aparece como uma tomada de partido do governo em favor dos setores ou classes que têm seus rendimentos elevados pela decisão. A contestação desta arbitragem leva não apenas ao desgaste político do governo ${ }^{6}$, mas também a uma demanda por uma isonomia de tratamento, que pode levar o governo a patrocinar uma espiral câmbio-salários-tarifas-preços.

6 Cooper, (1971, p.28-9) sublinha este tipo de conseqüência polftica, fazendo referência a um teste simples, a partir de uma pesquisa sobre episódios de desvalorização, do qual resultou que $30 \%$ dos govemos que desvalorizaram, calram num prazo de um ano, enquanto que $60 \%$ dos ministros da Fazenda foram destituldos. Por comparação, num grupo de palses com caracteristicas semelhantes, mas que não desvalorizaram, a queda de govemos no prazo de um ano foi de apenas $14 \%$. 
Há, pois, muitas razōes para que as autoridades evitem apontar muito para cima na sua tentativa de acertar o preço adequado para a moeda estrangeira.

Suponhamos então que o governo fixa a taxa de câmbio num nivel que se revele muito baixo, e que produza déficits em transações correntes superiores à possibilidade de financiamento externo. A redução das reservas resultante revelaria a existência de uma situação improjetável. Diante dela restariam ao governo três alternativas: suspender a conversibilidade, criando sucessivas restrições cambiais (limitação das operaçōes autorizadas da câmbio, proibições de importações, centralização cambial, etc); desvalorizar o câmbio, transformando a âncora em detonador de pressões inflacionárias; realizar uma política monetária draconiana, capaz de tornar a taxa de câmbio em vigor sustentável.

As restriçōes à conversibilidade, embora evitando temporariarnente a desvalorização, apareceria, aos olhos dos agentes econômicos, como o reconhecimento da insustentabilidade da taxa de câmbio, retirando toda a eficácia da âncora. A terceira hipótese constituiria, assim, a alternativa mais consistente com a concepção do programa de estabilização. Muito sinteticamente ela significaria que o governo teria que manter inalterado o crédito doméstico llquido, e deixar que a queda das reservas provocasse uma redução da base monetária capaz de contrair preços, e devolver competitividades aos produtos domésticos 7 , o que parece, para dizer o mínimo, implauslvel.

De tudo o que foi dito acima, conclui-se que um erro de subestimativa na avaliação da taxa de câmbio de equilíbrio cria enormes dificuldades para um plano de estabilização. Principalmente em se tratando de um programa radical - como o implementado no Brasil em março de 1990 -, que objetive transitar de uma situação de inflação muito alta - virtualmente explosiva - para um mundo com estabilidade e, portanto, sem indexação (inclusive do câmbio). Restaria indagar, contudo, se o governo não poderia dispor de técnicas que the permitissem aproximar-

7 Na perspectiva do "monetarismo global", a lei do preço único jå se encarregaria, a priori, de colocar os preços domésticos no seu devido lugar (via arbitragem). Os déficits do balanço de pagamentos prosseguiriam, entretanto, até que o estoque de moeda baixasse ao nivel desejado pela comunidade. $A$ única coisa que o governo poderia fazer seria promover, ele mesmo, a redução do estoque monetário via contraçăo do crédito doméstico liquido, de forma a preservar suas reservas. Nas palavras de Frenkel e Johnson (1977, p.29): "In a fixed exchange rate world, a country controls $\vec{s}^{\prime}$ neither its price level nor its quantity of domestic money in anything but the short tem: its money supply is endogenous, and what it controls by credit policy is simply the International reserve portion of the monetary base". 
se suficientemente da taxa de equilibrio, de maneira que os erros caíssem dentro de um intervalo manejável.

\section{A INCERTA BUSCA DO EQUILIBBRIO}

A primeira dificuldade no caminho de um diagnóstico técnico do atraso cambial a ser superado, está envolvida na própria noção de taxa de equilíbrio. Sem enveredar por esta complexa discussão ${ }^{8}$, cabe chamar a atenção, pelo menos, para o fato de que a definição depende, antes de mais nada, das próprias características do regime cambial. Num regime em que haja conversibilidade ampla e irrestrita, a demanda por moeda estrangeira no mercado de câmbio (único) tem como um de seus determinantes o desejo da sociedade de manter uma parte de sua riqueza na forma de moeda estrangeira (ou outros ativos financeiros externos de curto prazo). Se, ao contrário, as compras de câmbio estão oficialmente limitadas a operações comerciais e a operaçōes financeiras de natureza fundamentalmente transacional (isto é, vinculadas ao comércio exterior), então a curva de demanda além de se situar à esquerda da anterior, tende a ser muito menos volátil.

Para os propósitios da presente discussão, a taxa de equilíbrio poderia ser definida, sem maior rigor, como aquela capaz de induzir à formação de um saldo de transações correntes compativel com o influxo liquido esperado de capitais de médio e longo prazo. Seria um conceito que guardaria uma semelhança com a noção de equilibrio fundamental do balanço de pagamentos ${ }^{9}$. Avaliado o ingresso de capitais sustentável, caberia então estimar a taxa de câmbio compatível com o déficit (se for o caso) de transaçōes correntes possiveis. Para tanto se procederia a um cálculo baseado na regra da paridade do poder de compra da moe-

8 Williamson (1985, p.13-7) distingue três conceitos de equiltbrio cambial, que podem divergir acentuadamente: o equilbrio de mercado, correspondente à taxa de cåmbio que iguala oferta e demanda de divisas sem qualquer intervençăo das autoridades; a taxa de equilthrio fundamental (definida por referência à concepção de desequillbrio fundamental, constante dos estatutos do FMl), e que seria aquela capaz de gerar um saldo de transaçס̋es correntes igual ao fluxo de capital subjacente ao longo de um ciclo; e a taxa de equilbrio corrente, como aquela capaz de igualar os rendimentos dos ativos intemos e externos comparâveis, com base nas informaçőes correntes disponiveis.

9 A diferença em relação ao conceito de equilibrio fundamental é que os fluxos de capitais sustentáveis năo resultam basicamente dos "determinantes reais" - propensão a poupar e produtividade - mas de fatores subjetivos - como a (des)confiança no devedor soberano - e poIfticos. 
da, tomando como base um periodo em que o saldo observado fosse satisfatório. Mas as objeçōes que se pode fazer a tais procedimentos, principalmente no caso brasileiro atual, parecem insuperáveis. Com efejto, as transformaçōes por que passou a economia brasileira nos anos 80 , e os surtos de aceleração inflacionária do final da década, provocaram alterações de parâmetros que, praticamente, inviabilizam a identificação ex-ante de um nivel apropriado para o câmbio. Para tanto, observemos os dois componentes da definição de câmbio de equilíbrio.

No que se refere à avaliação do saldo de transações correntes correspondente a diferentes níveis de taxa de câmbio, podemos registrar as seguintes perturbações:

- as mudanças na estrutura produtiva, que alteraram profundamente a composição e o volume dos fluxos de exportação e importação ao longo da primeira metade da década, reduziram a relevância das informações sobre a taxa de câmbio real do perlodo anterior a (digamos) 1983-84;

- os surtos de aceleração inflacionária da segunda metade da década de 80 provocaram sucessivas distorções de preços relativos, que tornaram os índices gerais de preços, com os quais se avalia as taxas de câmbio reais, cada vez menos representativos da evolução dos custos e preços de setores particulares ${ }^{10}$;

- as profundas mudanças em curso no sentido da liberalicação das importações - eliminação de importantes barreiras não tarifárias, e redução de tarifas - tendem a promover um deslocamento significativo, mas difícil de ser avaliado na curva de demanda de importações.

Por outro lado, o fluxo líquido de capitais sustentado depende não apenas da renegociação da divida externa, mas também do sucesso do processo de estabilização de preços, e da própria retomada do, crescimento.

Em suma, as mudanças parametrais em curso, ou verificadas ao longo da década passada, certamente tornaram os indicadores baseados na paridade do poder de compra da moeda, um guia inadequado para a fixação da taxa de câmbio. Conseqüentemente, diante da sensa-

10 Usando a matriz de relaçóes intersetoriais do IBGE, Kume (1988) mostrou a existência de uma grande amplitude nas defasagens cambiais dos diferentes setores da indústria (de $1,8 \%$ a $37,8 \%$ para o cruzado/dollar, e de $-21,1 \%$ a $18,7 \%$ para o cruzado/cesta de moedas) no perfodo março-86 a março-88, tormando menos significativa a idéia de uma determinada defasagem cambial média. 
ção de que alteraçōes de grande magnitude teriam que ser realizadas no valor externo da moeda, a alternativa mais familiar, da fixação da taxa de câmbio colocava o governo diante da contingência de arbitrar um preço crucial da economia em condições de escassa visibilidade e, portanto, com um risco de errar bastante elevado. A opção do governo por uma alternativa mais radical de mudança de regime cambial aparentemente contornou este problema, ao mesmo tempo em que redefiniu as relações entre o câmbio e a política antiinflacionária.

\section{O REGIME DE TAXAS FLUTUANTES: A SOLUÇĀO E SEUS LIMITES}

As principais vantagens da introdução do regime de taxas de câmbio flutuantes, à luz da discussão acima, seriam: a possibilidade de lançar mão do mercado como um instrumento de aproximação da taxa de câmbio de equilíbrio; a compatibilização do novo regime com a política monetária empregada no programa de estabilização; e a despolitização da variável câmbio. Sua conseqüência mais indesejável seria o aumento da volatilidade da taxa de câmbio, prejudicando, eventualmente, o desempenho do comércio exterior. Antes de examinar estes pontos, cabe um breve exame das caracteristicas especificas do novo regime cambial.

A redução da esfera de intervenção do governo no mercado cambial, pode ser entendida em dois sentidos distintos, embora freqüentemente confundidos, a saber. a liberaçắo do preço da moeda estrangeira - o que equivale à instituição de um sistema de taxas de câmbio flutuantes; e a liberação dos limites quantitativos para a aquisição de divisas para quaisquer finalidades.

A liberalização pode ser parcial, em qualquer dos dois sentidos acima. Assim, pode haver uma combinação de câmbio flutuante com restrições à conversibilidade, como no caso atual do câmbio-turismo, e no caso histórico do regime de leilões, da instrução 70 da extinta SUMOC. Mas também podem conviver, lado a lado, uma razoável liberdade de acesso ao mercado de câmbio, com a fixação da taxa de câmbio pelas autoridades, como foi o caso do sistema adotado pelas naçōes mais desenvolvidas, de finais dos anos 50 até o colapso da ordem de Bretton Woods. Entre cada uma destas combinaçōes "puras", existem ainda inúmeras situaçōes intermediárias, caracterizadas por distintos graus de intervenção na formação da taxa de câmbio, e por diferencia- 
dos níveis de restrição à entrada no mercado de câmbio.

A cada combinação corresponde um regime cambial com caracteristicas e propriedades distintas. $O$ quadro a seguir resume algumas das principais propriedades das quatro combinações puras anteriormente mencionadas. No regime de taxas livremente flutuantes sem restriçōes cambiais, por exemplo, o ajuste automático da demanda e oferta de divisas, via flutuação de seu preço, eliminaria a necessidade das autoridades monetárias de intervir como compradoras ou vendedoras no mercado de câmbio, tornando a base monetária controlável através da dosagem do crédito doméstico liquido ${ }^{11}$.

É curioso notar que, no caso brasileiro recente, um argumento freqüentemente utilizado contra a introdução do câmbio flutuante, fazia referência à escassez de reservas que o governo dispunha por ocasião da implantação do novo sistema. Este tipo de objeção decorria, na verdade, de uma fusão, no conceito de liberalização, das noçōes distintas de flutuação e conversibilidade. Enquanto critica à livre conversibilidade, 0 argumento seria procedente. De fato, num sistema de câmbio fixo, a introdução da conversibilidade plena exige que o governo disponha de um volume de reservas suficiente para atender - a taxa de câmbio fixada toda a demanda adicional por divisas, que decorre da ampliação da possibilidade de efetivar livremente a aquisição de moeda estrangeira para quaisquer fins; e, persistindo o desequilibrio dos fluxos, as autoridades são obrigadas a adotar políticas monetária e fiscal contracionistas, se quiserem sustentar a paridade adotada.

11 Do balancete das autoridades monetárias, temos que a base monetária é igual à soma das reservas com $o$ crédito doméstico lfquido ( $B=R=C D L$ ). Na medida em que as autoridades năo sáo obrigadas a alterar seu estoque de reservas $(R)$ para sustentar a taxa de câmbio, elas dispóem dos meios para controlar $\mathrm{B}$, já que o $\mathrm{CDL}$ é esseincialmente uma variável de polftica económica. Uma outra dimensáo da capacidade para operar a poltitica monetária éa autonomia que cada naçăo ganha, sob este regime, para perseguir seus próprios objetivos de estabilidade intema, como argumentou Friedman (1953) em sua defesa do regime de cåmbio flutuante. 


\section{PROPRIEDADES DE DIFERENTES REGIMES CAMBIAIS}

\begin{tabular}{|c|c|c|c|c|}
\hline & & $\begin{array}{l}\text { Necessidade } \\
\text { de } \\
\text { Reservas }\end{array}$ & $\begin{array}{l}\text { Controle da } \\
\text { Oferta de Moeda } \\
\text { Pelas Autoridades }\end{array}$ & $\begin{array}{l}\text { Ajustamento a um } \\
\text { Desequilfbrio } \\
\text { Cambial }\end{array}$ \\
\hline \multirow{2}{*}{$\begin{array}{l}\text { Câmbio } \\
\text { Flutuante }\end{array}$} & $\begin{array}{l}\text { C/Conversi- } \\
\text { bilidade }\end{array}$ & Não & $\operatorname{Sim}$ & $\begin{array}{l}\text { Elevaçăo da } \\
\text { Taxa de Cåmbio }\end{array}$ \\
\hline & $\begin{array}{l}\text { C/Restriçőes } \\
\text { Cambiais }\end{array}$ & Năo & Sim & $\begin{array}{l}\text { Elev.Câmbio + } \\
\text { Restr.Adicionais }\end{array}$ \\
\hline \multirow{2}{*}{$\begin{array}{l}\text { Câmbio Fixo } \\
\text { (ou Indexado) }\end{array}$} & $\begin{array}{l}\text { C/Conversi- } \\
\text { bilidade }\end{array}$ & Sim,Máxima & Não & $\begin{array}{l}\text { Perda de Reservas + } \\
\text { Pol.Mon/Fiscal Contr. }\end{array}$ \\
\hline & $\begin{array}{l}\text { C/Restriçбoes } \\
\text { Cambiais }\end{array}$ & Sim & Parcial & $\begin{array}{l}\text { Perda de Reservas + } \\
\text { Restr.Adicionais }\end{array}$ \\
\hline
\end{tabular}

De que maneira poderíamos situar o novo regime cambial brasileiro dentro do quadro acima? Em princípio, seria um regime de câmbio flutuante sem livre conversibilidade. Em particular, estaria vedada a possibilidade de compra de moeda estrangeira, no mercado "oficial" flutuante, para fins de retenção como ativo de reserva. Teriamos, assim, uma fixação do preço da divisa pelo mercado, mas em resposta à oferta e demanda transacionais por câmbio.

Ocorre, porém, que longe de uma flutuação pura - que de resto não é praticada em lugar algum -, a experiência brasileira tem revelado, nos seus primeiros meses, uma intervenção bastante importante das autoridades no mercado de câmbio. Apesar de serem desconhecidas quaisquer metas do governo em relação ao rumo da taxa de câmbio, é inegável que estamos, pelo menos até o presente, diante de um caso de flutuação administrada. Concretamente, de abril a junho de 1990, o Banco Central adquiriu para suas reservas um montante de divisas equivalente a $25 \%$ do fechamento de câmbio de exportaçōes do período ${ }^{12}$.

12 De acordo com as informaçóes fornecidas pelo Banco Central, as reservas no conceito de caixa sofreram um aumento de US $\$ 2416$ milhőes no trimestre abril-junho, enquanto o fechamento de contratos de exportaçăo atingiu US\$ 9601 milhőes. Nǎo incorporamos os dados referentes à primeira quinzena de implantaçăo do cåmbio flutuante ( 16 a 31 de março), porque a escassez extrema de liquidez levou a uma venda excepcional de dólares pelo setor privado, numa conjuntura absolutamente atipica. 
Não se deve concluir, contudo, que o intervencionismo estaria desregulando os ponteiros do mercado, comprometendo um instrumento supostamente capaz de guiar o preço da moeda estrangeira para o equilíbrio (fundamental). Pelo contrário, a experiência de 17 anos de flutuação dos países mais desenvolvidos já tornou evidente que, ao contrário do que se supunha, o desalinhamento tem sido um problema ainda mais sério do que a volatilidade sob o sistema de câmbio flutuante.

Refletindo sobre a experiência de flutuação dos países avançados, Krugman (1989) identifica uma relação estreita entre flutuação e desalinhamento. Seu argumento funda-se na constatação de que, no caso de produtos manufaturados diferenciados, que compõem a maior parte do comércio entre os países avançados (e atualmente, também do Brasil), a penetração no mercado internacional exige que as empresas incorram em pesados custos irreversíveis (em caso de abandono do mercado externo). De acordo com seu modelo ("Sunk Cost Model"), o peso destes investimentos irreversíveis faz com que o comércio torne-se razoavelmente insensivel às taxas de câmbio (pelo menos para valores dentro de uma faixa de variação relativarnente ampla), particularmente quando elas são muito voláteis ${ }^{13}$. A lentidão da resposta dos fluxos comerciais a variações cambiais ${ }^{14}$, lado a lado com o comportamento desestabilizador dos fluxos financeiros num regime de taxas flutuantes, resultou numa experiência caracterizada por evidentes e clamorosas falhas do mercado.

Três lições podem ser, a meu ver, extraídas do experimento internacional, com vistas à operação do sistema brasileiro. Em primeiro lúgar, que a preocupação em administrar a flutuação deveria ser assumida como um meio de reduzir a volatilidade da taxa de câmbio, até mesmo como forma de rumar com maior visibilidade em direção a uma situação sustentável de balanço de pagamentos. Ainda com o propósito de reduzir a volatilidade, parece recomendável - pelo menos durante a fase de busca de uma taxa (ou um intervalo) de equilíbrio para o câmbio - delimitar as possibilidades de acesso ao mercado de câmbio para a demanda fundamentalmente transacional. A este respeito, cabe apontar

13 "The obvious point is...that a firm will be willing to break into a market only if it expects to cover its sunk costs, and that once the costs are sunk it will be willing to stay in a market even if it is able to cover only its variable cost" (Krugrian, 1989, p.45).

14 Se os fluxos de exportaçăo e importaçăo reagissem prontamente às mudanças nas taxas de cámbio, eles funcionariam como um mecanismo de correção automática dos desvios. 
aqui que uma das características do regime cambial inaugurado com o Plano Collor, consiste na autorização concedida aos bancos de que mantenham saldos em divisas (posiçōes compradas) ilimitados ${ }^{15}$. Neste curto periodo de existência do novo sistema, já tem sido possivel notar o impacto desta característica, na forma de uma acentuação das oscilaçōes cambiais - com a demanda dos bancos engrossando substancialmente a ponta compradora de divisas -- sempre que se antecipa uma pressão futura sobre o mercado.

Uma terceira advertência diz respeito ao risco de uma avaliação incorreta da situação do câmbio, devido ao fenômeno da histerese. Uma eventual permanência de um resultado satisfatório do balanço de pagamentos pode ter a ver com uma realidade cambial (e de incentivos) passada, e que permanece por inércia, em função de investimentos para penetração no mercado externo, realizados em outras circunstâncias. Isto deve relativizar as observaçōes sobre as relaçōes presentes entre câmbio e fluxos do balanço de pagamentos, pelo menos enquanto perdurar a atmosfera de grandes incertezas associada às vicissitudes da economia brasileira nos anos mais recentes.

Com todas as ressalvas acima, o regime de câmbio flutuante ainda parece uma alternativa superior para lidar com as dificuldades cambiais na transição para uma economia estável. Quanto mais não seja porque permite compatibilizar a desindexação da economia com uma flexibilidade indispensável (dada a enorme distorção/desalinhamento ocorrido nos anos recentes) para rastrear um nivel satisfatório para a taxa de câmbio.

Mas há uma outra face do novo sistema cambial que parece adequar-se ao plano de estabilização adotado em março de 1990. É que ele garante uma liberdade de ação inédita à política monetária, na medida em que o governo estaria desembaraçado da obrigação de expandir a base monetária em resposta a um aumento na oferta (ou contração da demanda) de moeda estrangeira. Isto evitaria, por exemplo, o problema ocorrido por ocasião do Plano Verão, quando a contenção monetária foi parcialmente neutralizada pelo volumoso ingresso de recursos externos (via adiantamentos sobre contratos de câmbio) atraídos pela elevação das taxas de juros internas. Evitaria, também, que uma interrupção (ou

15 A obrigatoriedade de que os bancos depositem em conta do Banco Central no exterior o valor que exceder a US\$ 1 milhăo não altera esta caracterlstica, na medida em que os valores excedentes continuam sendo ativos financeiros em dólar, de propriedade dos bancos. 
redução) dos pagamentos de juros ao exterior fosse inócua para fechar o "hiato fiscal", dada a acumulação resultante de reservas ${ }^{16}$. Em suma, o câmbio flutuante é uma condição para que se possa praticar uma polltica monetária ativa - que é um dos pilares centrais do plano de estabilização em curso.

\section{OBSERVAÇŌES FINAIS}

Ao longo deste trabalho, procurou-se argumentar que a fixação da taxa de câmbio, como âncora do programa de estabilização da economia, traria um elevado risco de criar uma situação insustentável de balanço de pagamentos, que acabaria por comprometer profundamente a própria política antiinflacionária. Entre outras razões porque, no rastro das transformações por que passou a economia na década de 80 , e da desorganização provocada pela inflação nos anos mais recentes, os gestores da política econômica não dispõem de um guia minimamente confiável para determinar uma taxa de câmbio compativel com uma situação sustentável do balanço de pagamentos. Neste contexto, a implantação de um regime de câmbio flutuante tem a inestimável vantagem de fornecer maior flexibilidade para um processo de tateio na busca de um preço de "equilíbrio" para a moeda estrangeira. Além disso, é um sistema que viabiliza a prática de uma política monetária ativa e, portanto, coerente com a natureza do plano de estabilização adotado pelo governo empossado em março de 1990.

Mas o regime de câmbio flutuante não é nenhuma panacéia. A experiência dos países avançados nos últimos 17 anos mostrou que não só se confirmaram as piores suspeitas de que quanto maior a flexibili-

16 Bacha (1989, p.228) conclui, a partir de seu modelo de três hiatos que "Os palses que enfrentam uma restrição fiscal - e não têm restriçס̄es de divisas ou de poupança - acham-se... em posição diffcil para solicitarem melhores condiçס̋es em relaçăo à dfida. Eles teriam falta de capacidade de absorçăo, e nesse caso as reservas cresceriam indefinidamente, ou retomariam o crescimento com inflaçăo".

De fato, no contexto de curto prazo, em que o combate frontal à inflaçăo é uma prioridade indisputada, a acumulaçăo de reservas pode ser, em momentos crhicos, preterida em funçăo do controle monetário. $E$, neste caso, o sistema de câmbio flutuante, na medida em que permite que o governo se abstenha a qualquer momento de adquirir reservas, parece um mecanismo muito mais ágil, eficiente, e com conseqüências estruturais menos negativas, do que uma repressão ao superávit comercial baseada em restriçð̋es a exportaçóøs e incentivos a importaçס̄es. Em relação a esta questão especffica, e em funçẵo das condiçóes deste câmbio de exportaçăo, ou pela autorizaçăo, já comentada, de posiçס̋es cambiais compradas sem limites) poderia eventualmente ser justificada. 
dade, maior a instabilidade das taxas (provocada pelos fluxos especulativos de capital), como evidenciou que a flutuação livre não é capaz sequer de levar ao alinhamento das taxas de câmbio, de forma a produzir equilibrios sustentáveis dos balanços de pagamentos. Ao contrário, os desalinhamentos e os desequilíbrios dos balanços de pagamentos na década de 80 foram incomparavelmente superiores aos verificados durante o período de taxas fixas (ajustáveis) de Bretton Woods. Esta realidade tem levado muitos dos defensores das taxas flutuantes, nos paises avançados, a rever suas posiçōes.

As observações acima nos levam a considerar o regime de taxas flutuantes recentemente implantado no Brasil como uma instituição atraente para um perlodo de transição, mas não como uma solução de longo prazo. Não foram examinadas aqui possiveis alternativas mais duradouras. Se alguma indicação pode ser deduzida da argumentação desenvolvida, ela pende para uma opção pela estabilidade das cotaçōes das moedas estrangeiras. Contudo, face à rigidez introduzida no sistema por uma taxa fixa, por um lado, e dado o esgotamento da experiência de indexação cambial, por outro, um câmbio administrado, por meio da fixação de intervalos relativamente estreitos para a flutuação, parece ser uma meta adequada para o futuro.

\section{BIBLIOGRAFIA}

BACHA, Edmar L. Um modelo de Três Hiatos. Pesquisa e Planejamento Econômico. v.19, n.2, p.213-32, ago. 1989.

COOPER, R.N. Currency Devaluation in Developing Countries. Essays in International Finance. Principton University, n. 86, 1971.

DORNBUSCH, R. Inflaçăo, Taxas de Câmbio e Estabilização. Pesquisa e Planejamento Económico, v. 16, n. 2, p.321-50, ago. 1986.

FRENKEL, J. A. \& JOHNSON, H.G. The Monetary Approach to the Balance of Payments. Essential Concepts and Historical Origins. In: - (eds.) The Monetary Approach to the Balance of Payments. London, George Allen \& Unwin, 1977.

FRIEDMAN, M. The Case for Flexible Exchange Rates. In: -

Essays In Positive Economics. Chicago, The University of Chicago Prèss, 1953.

KRUGMAN, P. Exchange Rate Instability. The MIT Press, 1989: 
KUME, H. Defasagem Justifica Mudança? Revista Brasileira de Comércio Exterior. n.18, jul./ago. 1988.

SUPLICY, E. M. Os Efeitos das Minidesvalorizaçōes na Economia Brasileira. Rio de Janeiro, FGV, 1976.

WILLIAMSON, J. The Exchange Rate System. Institute for International Economics, 1985.

\section{ABSTRACT \\ THE CASE FOR FLOATING EXCHANGE RATES IN A TRANSITION PHASE}

This article seeks to discuss questions related to exchange rate policy in the context of a transition from a high inflation situation, such as the one experienced by the Brazilian economy in recent years, to a regime of price stability. It is argued that the rising inflation in the 80s led to an exhaustion of the mini-devaluation system. The huge problems associated with the setting of the exchange rate are discussed. It is concluded that, although the freely floating exchange rate system is not a desirable alternative for the long run, a regime of managed floating exchange rates does constitute the least troublesome one in the context of the transition to price stability. 